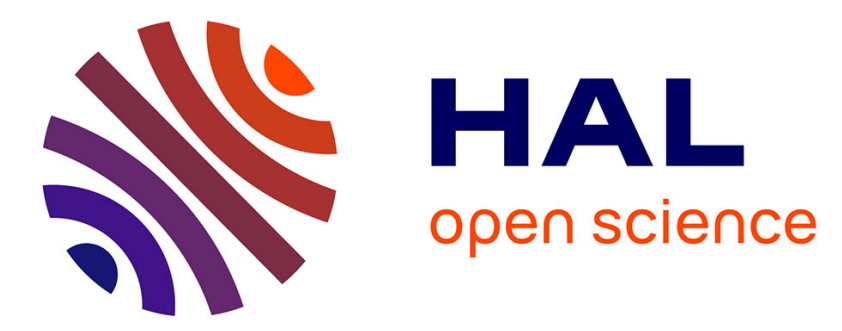

\title{
Theoretical studies of the spin coating process for the deposition of polymer-based Maxwellian liquids
}

Pierre Temple-Boyer, Laurent Mazenq, Jean-Baptiste Doucet, Véronique

Conédéra, Benoit Torbiero, Jérôme Launay

\section{- To cite this version:}

Pierre Temple-Boyer, Laurent Mazenq, Jean-Baptiste Doucet, Véronique Conédéra, Benoit Torbiero, et al.. Theoretical studies of the spin coating process for the deposition of polymer-based Maxwellian liquids. Microelectronic Engineering, 2010, 87 (2), pp.163-166. 10.1016/j.mee.2009.06.030 . hal01687852

\section{HAL Id: hal-01687852 \\ https://hal.laas.fr/hal-01687852}

Submitted on 18 Jan 2018

HAL is a multi-disciplinary open access archive for the deposit and dissemination of scientific research documents, whether they are published or not. The documents may come from teaching and research institutions in France or abroad, or from public or private research centers.
L'archive ouverte pluridisciplinaire HAL, est destinée au dépôt et à la diffusion de documents scientifiques de niveau recherche, publiés ou non, émanant des établissements d'enseignement et de recherche français ou étrangers, des laboratoires publics ou privés. 


\title{
Theoretical studies of the spin coating process
}

\section{for the deposition of polymer-based Maxwellian liquids}

\author{
P. Temple-Boyer, L. Mazenq, J.B. Doucet, \\ V. Conédéra, B. Torbiéro, J. Launay \\ CNRS; LAAS; 7 avenue du colonel Roche, F-31077 Toulouse, France \\ Université de Toulouse; UPS, INSA, INP, ISAE; LAAS; F-31077 Toulouse, France \\ E-mail: temple@laas.fr
}

\begin{abstract}
:
This paper deals with the study of spin coating processes for the deposition of polysiloxane-based thin films. Specific developments are proposed in order to adapt the hydrodynamic laws theory to the spin coating of Maxwellian liquids. Theoretical and experimental results are compared, evidencing a good fit and enabling to define the Maxwellian law for the studied polysiloxane polymer. Finally, the theoretical developments are successfully extended to the BCB 4026 and SU-8 3050 photosensitive resins.
\end{abstract}

Keywords : spin coating, Maxwellian liquids, polysiloxane, BCB resin, SU-8 resin 


\section{Introduction}

Within the framework of micro/nanotechnologies, polymer-based materials such as polymethylmethacrylate (PMMA) [1,2], poly-vinyl chloride (PVC) [3-5], poly-vinyl alcohol (PVA) [6,7], polysiloxane (PSX) [8], SU-8 epoxy resin [9-12], polydimethylsiloxane (PDMS) [13-17], benzocyclobutene (BCB) [18-22],.., have shown very promising potentialities for a wide range of applications: sacrificial layers techniques, surface micropatterning, micro/nanomaterials integration, dielectric insulation, packaging (from wafer to system level),... Nevertheless, whatever the polymer chemistry, the mass-fabrication requirement has been carried out through the development of specific micro/nanolithography processes based on inkjet printing, spray coating, micro/nano contact printing, micromoulding, serigraphy shadow mask patterning and of course photolithography. This last process is well adapted to wafer level packaging techniques. It is fully compatible with microtechnologies but requires a spinning process in order to deposit the photosensitive polymers layers on the wafer. This spin coating process has therefore to be studied in order to reach reproducibility and reliability for the realisation of specific microdevices. Such study has been performed for polymer-based Newtonian liquids [23] and has to be further developed for now-Newtonian ones.

This paper deals with the spin coating process theory applied to polymer-based Maxwellian liquids. The theoretical and experimental results are compared for the deposition and patterning of polysiloxane thin films by spin coating and photolithography techniques. Finally, the proposed theory is extended to two others commercial photosensitive polymers, i.e. the BCB 4026 and SU-8 3050 resins, currently used for wafer level packaging applications. 


\section{Experimental}

The polysiloxane (PSX) copolymer RMS-033 containing methacrylate groups was purchased from ABCR. The 3-(methacryloxy)propyl trimethoxysilane (MPTS), the 2,2dimethoxy-2-phenylacetophenone (DMPA) photo-initiator, the tetrahydrofuran (THF) solvent as well as the others standard chemical products used were obtained from Sigma-Aldrich.

According to previous studies [24,25], the photosensitive polymer was formed from 99\% of PSX and 1\% of DMPA photo-initiator, and then dissolved into THF to reach different dilutions $\mathrm{x}_{0}$. The volumic mass of the different polysiloxane solutions obtained was finally estimated by accurate weighing while their hydrodynamic properties, and more precisely their static and dynamic viscosity, were characterized using a Haake VT550 viscometer (table 1). The polysiloxane thin films were patterned according to the following process. After an MPTS/toluene silanisation step at $80^{\circ} \mathrm{C}$ to promote adherence on the silicon substrate, the PSX-based solution was deposited by spin coating using a SUSS GYRSET RC-8 spin coater. Then, after the THF solvent evaporation under nitrogen atmosphere, ultraviolet (UV) exposure was performed under a non-oxidising ambient using a Karl Suss MA-6 contact alignment system. Finally, after development into xylene, the PSX pattern thicknesses were studied using a TENCOR scan profiler. Thus, different spin coating deposition conditions were tested for different polysiloxane solutions in order to compare experimental and theoretical results.

Finally, the commercial BCB 4026 and SU-8 3050 photosensitive resins were respectively purchased from Dow chemical and Microchem. Then, according to the technical specifications, spin coating deposition processes have been used in order to pattern thick layers by photolithography. 


\section{Results and discussion}

\subsection{Theoretic study of the spin coating process applied to Maxwellian liquids}

According to the Ostwald law, a typical relation between the sheer stress $\tau$ and the sheer velocity $\square$.characterizes the rheology-based properties of Maxwellian liquids:

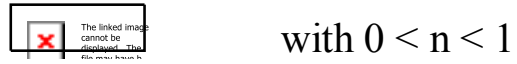

Starting from previous studies [23], the hydrodynamics of the spin coating process has been developed while taking into account equation 1. Thus, when a film of Maxwellian solution is deposited on the horizontal surface of a circular substrate, the force balance yields (while neglecting the gravity forces):

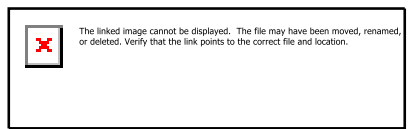

where $\mathrm{z}$ is the rotation axis, $\mathrm{r}$ stands for the radial parameter, $\mathrm{v}$ is the radial speed, $\omega$ is the rotation speed, $\eta$ and $\rho$ are the static viscosity and the volumic mass of the studied liquid.

For a given $r$ value, equation (3) can be integrated two times in order to determine the radial speed $\mathrm{v}$ as a function of $\mathrm{z}$ :

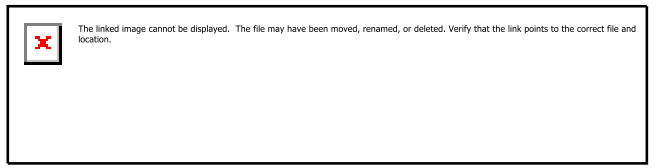

where $v=\eta / \rho$ is the dynamic viscosity and $h$ is the Maxwellian solution thickness.

Then, the equation of continuity gives:

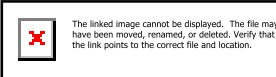

where $\mathrm{q}(\mathrm{r})$ is the total radial flow by circumference unit:

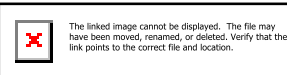


According to equations (3) and (5), equation (4) becomes:

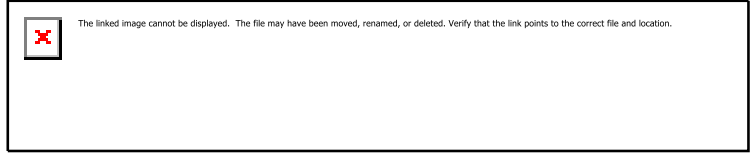

In order to solve equation (6), the variable separation method has been chosen. Thus, the Maxwellian solution thickness $h(r, t)$ has been written as following: $h(r, t)=R(r) . T(t)$. This leads to:

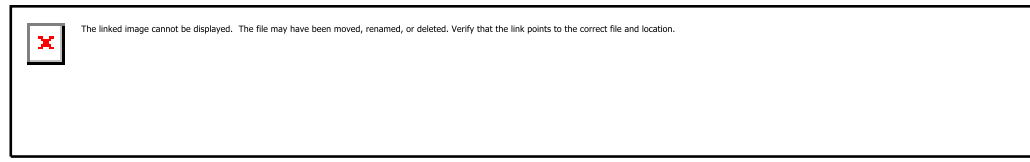

The two differential equations respectively relative to the $\mathrm{R}(\mathrm{r})$ and $\mathrm{T}(\mathrm{t})$ functions defined in equation (7) can finally be solved in order to determine the solution thickness $h(r, t):$

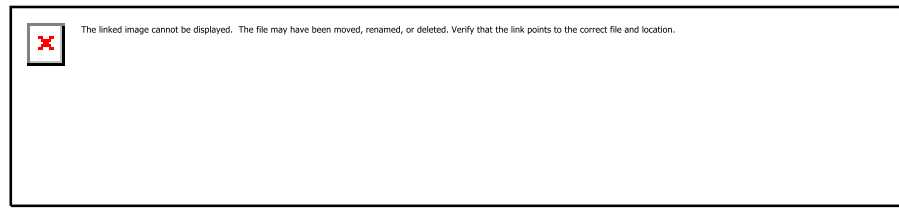

In order to have a better definition of the constant parameter $\mathrm{A}$, it has been assumed that, as a starting point, a solution thickness $\mathrm{h}_{0}$ is defined for an arbitrary radial parameter $\mathrm{r}_{0}$. Therefore, equation (8) becomes:

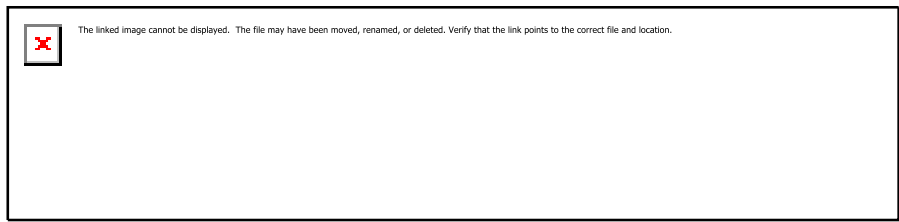

The solution $h(r, t)$ given by equation (9) for the Maxwellian solution thickness can be criticized according to several points of discussion.

First, since the $\mathrm{n}$ parameter ranges between 0 and 1 , the $\mathrm{h}(\mathrm{r}, \mathrm{t})$ function tends towards an infinite value when the radial parameter $r$ tends towards 0 , i.e. $h(0, t)=+\infty$. Such behaviour is not realistic and should be related to the non-consideration of the gravity forces in the theoretic model. 
Second, the $\mathrm{h}(\mathrm{r}, \mathrm{t})$ solution involves an arbitrary parameter $\mathrm{r}_{0}$ (as a mathematical consequence of the first point).

Third, the $\mathrm{h}(\mathrm{r}, \mathrm{t})$ function tends towards 0 when the time tends towards an infinite value, i.e. $h(r,+\infty)=0$. Again, such behaviour is not realistic and should be related to the non-consideration of the solution evaporation phenomena in our theoretic model.

In order to take into account these evaporation phenomena, the method developed by Meyerhoffer for Newtonian solutions [26] has been used. Indeed, for such liquids $(\mathrm{n}=1)$, equation (9) becomes (in agreement with Meyerhoffer calculations):

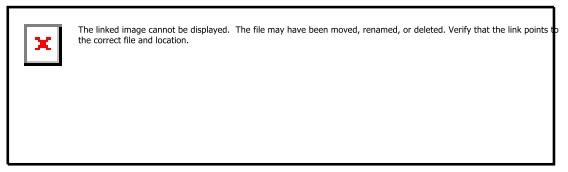

Thus, the polymer-based Maxwellian solution has been considered as a mix between a solid solute and a liquid solvent. To simplify with the theoretical aspect, the solute and solvent will be characterised by their equivalent thickness $s(r, t)$ and $1(r, t)$ respectively. With these definitions, the solution total thickness $\mathrm{h}(\mathrm{r}, \mathrm{t})$ and the solute concentration $\mathrm{c}(\mathrm{r}, \mathrm{t})$ will be given by:
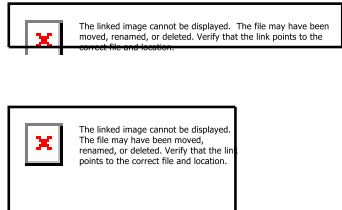

By taking into account evaporation phenomena, since the kinematic viscosity $v$ depends on the solute concentration $\mathrm{c}(\mathrm{r}, \mathrm{t})$ and therefore of the solution thickness $\mathrm{h}(\mathrm{r}, \mathrm{t})$, equation 6 can no longer be solved. However, taking into account the outflow and the evaporation terms, it can be separated as follows for the solute and the solvent:

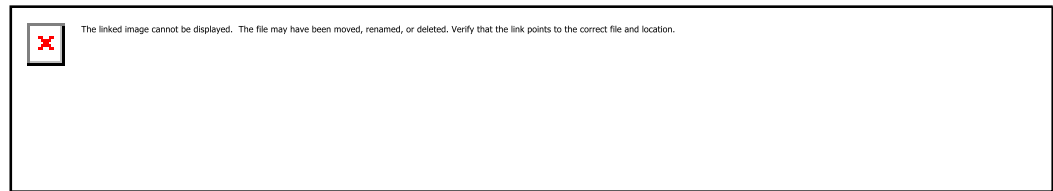

$$
\mathrm{x}
$$


where e is the solvent surfacic evaporation per unit time.

The resolution of this mathematical system is not possible. However, Meyerhofer has shown numerically that the solution can be approximated thanks to two different hydrodynamic regimes [26].

First, the solution is characterised by high thickness $\mathrm{h}(\mathrm{r}, \mathrm{t})$. The evaporation term is therefore negligible, i.e. e $<<|\mathrm{F}(\mathrm{r}, \mathrm{t})|$, and the solution thickness decrease is controlled by the outflow term. According to equations (13) and (14), this initial hydrodynamic regime is characterised by:

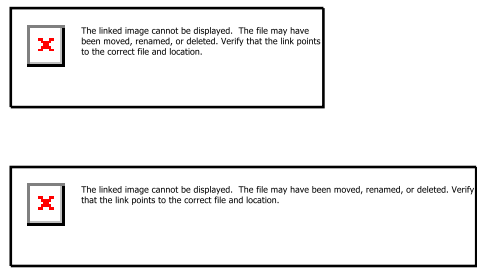

According to equations (12), (15) and (16), the concentration $\mathrm{c}(\mathrm{r}, \mathrm{t})$ is found to not depend on the time parameter, i.e. $\mathrm{c}(\mathrm{r}, \mathrm{t})=\mathrm{c}_{0}(\mathrm{r})$ where $\mathrm{c}_{0}(\mathrm{r})$ is the initial concentration for $\mathrm{a}$ given radius parameter.

Second, with the thickness $\mathrm{h}(\mathrm{r}, \mathrm{t})$ decreases, the outflow term also decreases and becomes negligible, i.e. $|\mathrm{F}(\mathrm{r}, \mathrm{t})|<<\mathrm{e}$, and the solution thickness decrease is finally controlled by the evaporation term. Thus, integration of equations (13) and (14) leads to the description of the final hydrodynamic regime:

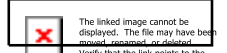

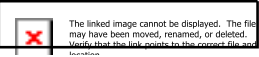

where $\mathrm{st}_{\mathrm{t}}(\mathrm{r})$ and $\mathrm{l}_{\mathrm{t}}(\mathrm{r})$ are integration constants related to the transition between the initial and the final regimes.

For the arbitrary radius parameter $\mathrm{r}$, the final thickness $\mathrm{h}_{\mathrm{f}}$ will be reached when there is no longer solvent in the Maxwellian solution, i.e. when $l_{\mathrm{f}}=0$. Therefore, it will be given by:

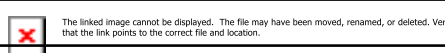


The transition between the initial and the final regimes is assumed to occur when the outflow and evaporation terms are equal in absolute value, i.e. $(1-\mathrm{c})\left|\mathrm{F}\left(\mathrm{r}_{0}, \mathrm{t}\right)\right|=$ e. This leads to the determination of the transition thickness $\mathrm{h}_{\mathrm{t}}$ :

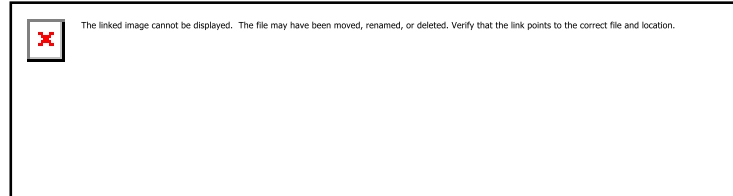

Finally, according to equations (19) and (20), the final thickness $\mathrm{h}_{\mathrm{f}}$ is given by:

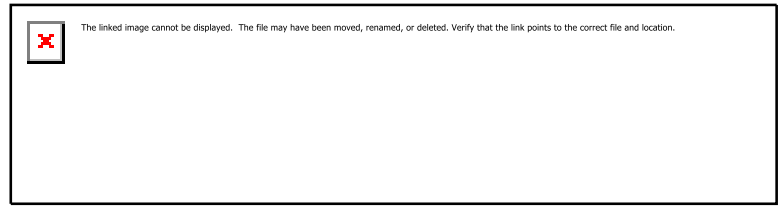

Thus, the equation (21) allows the determination of the final thickness $\mathrm{h}_{\mathrm{f}}$ deposited by spin coating. For a Newtonian solution $(n=1)$, it is equivalent to the relation defined by Meyerhofer [26]:

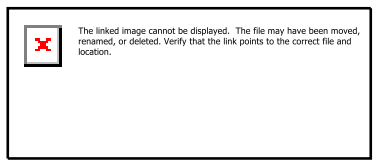

For a Maxwellian solution $(0<\mathrm{n}<1)$, equation (21) still involves the arbitrary radius parameter $r_{0}$ (as a consequence of the non-consideration of the gravity forces in the theoretic model, see below). This mathematical consequence prevents from having any information on the solvent surfacic evaporation per unit time parameter e. Nevertheless, equation (21) can be simplified in order to highlight the relation between the final thickness $\mathrm{h}_{\mathrm{f}}$ and the main parameter of the spin coating process, i.e. the rotation speed $\omega$ :

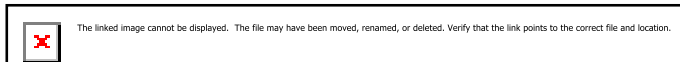

Thus, by studying the variation of $h_{f}$ with $\omega$, it will be possible to determine the $n$ parameter and therefore to define the Maxwellian properties of a liquid solution. 


\subsection{Study of polymer-based solutions}

In previous papers, the spin coating deposition and patterning of different polymerbased solutions have been presented. For the polyvinyl alcohol (PVA) polymer diluted in its solvent, i.e. water, the final thickness $h_{f}$ has been found to vary with $\omega^{-2 / 3}$, in agreement with the Meyerhofer model developed for Newtonian solutions (nPVA $=1)[23,26]$. Nevertheless, for the polysiloxane (PSX) polymer diluted into tetrahydrofuran (THF), no such agreement was obtained [25].

The different results obtained for the different polysiloxane-based solutions have been reported in table 2 . However, in order to analyse them, the logarithm of the final thickness $\mathrm{h}_{\mathrm{f}}$ (given in microns) has been represented as a function of the logarithm of the rotation speed $\omega$ (given in radians per second) on figure 1. Thus, whatever the polysiloxane dilution into THF and in agreement with the proposed theory, experimental results evidence a power law as following:

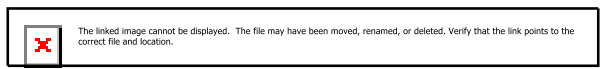

Finally, by fitting the theoretical equation and the experimental one (equations 23 and 24), it is possible to estimate for the polysiloxane RMS-033 the Maxwellian parameter $n$ of the Ostwald law (equation 1):

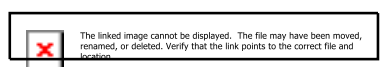

In order to validate our theoretical model, similar studies have been performed on two other commercial photosensitive polymers developed for thick-layer deposition: the BCB 4026 and the SU-8 3050 resins (table 3). Again, by representing the logarithm of the final thickness $\mathrm{h}_{\mathrm{f}}$ (given in microns) as a function of the logarithm of the rotation speed $\omega$ (given in radians per second), a power law has been evidenced for the two resins (figure 2). Finally, as 
previously, the Maxwellian parameter $\mathrm{n}$ of the Ostwald law has been estimated for both photoresists:

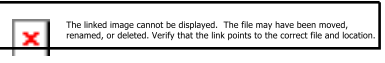

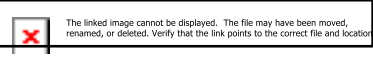

\section{Conclusion}

A theoretical model has been proposed for the spin coating of Maxwellian liquids. It is based on the hydrodynamics theory and includes the solvent evaporation phenomena. Even if some mathematical drawbacks prevent from determining some parameters like the solvent surfacic evaporation per unit time, a good fit has been obtained between experimental and theoretic results for different polymer-based, i.e. PSX RMS-033, BCB 4026 and SU-8 3050, Maxwellian solutions, enabling to define the Ostwald law main parameter. Such developments will be used in order to understand and optimise the thick photoresists spin coating and photolithography processes for wafer level packaging applications.

\section{References}

[1] C. Vieu, A. Pépin, Y. Chen, F. Carcenac, M. Méjias, A. Lébib, L. Manin Ferlazzo, L. Couraud, H. Launois, Electron beam lithography: resolution limits and applications, Applied surface science 164 (2000) 111-117

[2] B. Cui, Y. Cortot, T. Veres, Polyimides nanostructures fabricated by nanoimprint lithography and its applications, Microelectronics Engineering 83 (2006) 906-909.

[3] J. Bargon, W. Behnck, T. Weidenbrück, T. Ueno, Lithographic patterning of conducting polymers and their composites, Synthetic Metals 41 (1991) 1111-1114 
[4] J. Artigas, A. Beltran, C. Jimenez, J. Bartroli, J. Alonso, Development of a photopolymerisable membrane for calcium ion sensors - application to soil drainage waters, Analytica Chemica Acta 426 (2001) 3-10

[5] H.A. Arida, Development of a long-term stable organic membrane-based thin-film microsensor using new-type substrate surface treatment, Talanta 71 (2007) 1856-1860

[6] W. Sant, M.L. Pourciel-Gouzy, J. Launay, T. Do Conto, A. Martinez, P. Temple-Boyer, Development of chemical field effect transistors for the detection of urea, Sensors and Actuators B95 (2003) 309-314.

[7] W. Sant, M.L. Pourciel-Gouzy, J. Launay, T. Do Conto, R. Colin, A. Martinez, P. Temple-Boyer, Development of a creatinine-sensitive sensor for medical analysis, Sensors and Actuators B103 (2004) 260-264.

[8] I. Humenyuk, B. Torbiéro, S. Assié Souleille, R. Colin, X. Dollat, B. Franc, A. Martinez, P. Temple-Boyer, Development of $\mathrm{pNH}_{4}$-ISFET microsensors for water analysis, Microelectronics Journal 37 (2006) 475-479.

[9] C.G. Khan Malek, SU8 resist for low-cost X-ray patterning of high-resolution highaspect-ratio MEMS, Microelectronics Journal 33 (2002) 101-105.

[10] N. Arana, D. Puente, I. Ayerdi, E. Castaño, J. Berganzo, SU8 protective layers in liquid operating SAWs, Sensors and Actuators B118 (2006) 374-379

[11] P. Abgrall, V. Conédéra, H. Camon, A.M. Gué, N-T. Guyen, SU-8 as a structural material for labs-on-chips and microelectromechanical systems, Electrophoresis 28 (2007) 4539-4551

[12] S. Keller, G. Blagoi, M. Lillemose, D. Haeflinger, A. Boisen, Processing of thin SU8 films, Journal of Micromechanical Microengineering 18 (2008) 125020

[13] W.M. Choi, O.O. Park, A soft-imprint technique for submicron-scale patterns using a PDMS mold, Microelectronic Engineering 73-74 (2004) 178-183. 
[14] A. Plecis, Y. Chen, Fabrication of microfluidic devices based on glass-PDMS-glass technology, Microelectronic Engineering 84 (2007) 1265-1269.

[15] M.L. Pourciel-Gouzy, S. Assié-Souleille, L. Mazenq, J. Launay, P. Temple-Boyer, pHChemFET-based analysis devices for the bacterial activity monitoring, Sensors and Actuators B134 (2008) 339-344.

[16] I-S. Hwang, Y-S. Kim, S-J. Kim, B-K. Ju, J-H. Lee, A facile fabrication of semiconductor nanowires gas sensor using PDMS patterning and solution deposition, Sensors and Actuators B136 (2009) 224-229.

[17] S. Hsieh, Y-A. Cheng, C-W. Hsieh, Plasma induced patterning of polydimethylsiloxane surfaces, Y. Liu, Materials Science and Engineering B156 (2009) 18-23.

[18] M.E. Mills, P. Townsend, D. Castillo, S. Martin, A. Achen, Benzocyclobutene (DVS$\mathrm{BCB}$ ) polymer as an interlayer dielectric (ILD) materials, Microelectronic Engineering 33 (1997) 327-334.

[19] J. Oberhammer, F. Niklaus, G. Stemme, Selective wafer-level adhesive bonding with benzocyclobutene for fabrication of cavities, Sensors and Actuators A105 (2003) 297304.

[20] K. Lee, J. He, R. Clement, S. Massia, B. Kim, Biocompatible benzocyclobutene (BCB)-based neural implants with micro-fluidic channels, Biosensors and Bioelectronics 20 (2004) 404-407.

[21] A. Modafe, N. Ghalichechian, M. Powers, M. Khbeis, R. Ghodssi, Embedded benzocyclobutene in silicon: an integrated fabrication process for electrical and thermal isolation in MEMS, Microelectronic Engineering 82 (2005) 154-167.

[22] S. Soek, N. Rolland, P.A. Rolland, A novel packaging method using wafer-level BCB polymer bonding and glass wet-etching for RF applications, Sensors and Actuators A147 (2008) 677-682. 
[23] M.L. Pourciel-Gouzy, J. Launay, W. Sant, V. Conédéra, A. Martinez, P. Temple-Boyer, Development of photo-polymerisable polyvinyl alcohol for biotechnological applications, Sensors and Actuators B94 (2003) 330-336.

[24] W. Wroblewski, M. Chudy, A. Dybko, Z. Brzozka, $\mathrm{NH}_{4}{ }^{+}$-sensitive chemically modified field effect transistors based on siloxane membranes for flow-cell applications, Analytica Chemica Acta 401 (1999) 105-110.

[25] B. Torbiéro, M.L. Pourciel-Gouzy, I. Humenyuk, J.B. Doucet, A. Martinez, P. TempleBoyer, Mass patterning of polysiloxane layers using spin coating and photolithography techniques, Microelectronics Journal 37 (2006) 133-136.

[26] D. Meyerhofer, Characteristics of resist films produced by spinning, Journal of Applied Physics 49 (1978) 3993-3997. 


\section{Figures captions}

Table 1: Characteristics of the different polysiloxane-based solutions

Table 2: Deposited thickness $h_{f}$ for the different polysiloxane-based solutions

Table 3: Deposited thickness $h_{f}$ for the BCB 4026 and SU8 3050 photoresists

Figure 1: Variations of the final thickness logarithm with the rotation speed logarithm for the different polysiloxane-based solutions

Figure 2: Variations of the final thickness logarithm with the rotation speed logarithm for the BCB 4026 and SU8 3050 photoresists 


\begin{tabular}{|c|c|c|c|c|}
\hline PSX solution & S1 & S2 & S3 & S4 \\
\hline PSX/DMPA (99/1) volume $(\mathrm{mL})$ & 15.15 & 15.15 & 15.15 & 15.15 \\
\hline THF volume $(\mathrm{mL})$ & 1 & 3 & 5 & 7 \\
\hline dilution $\mathrm{x} 0$ & 0.94 & 0.83 & 0.75 & 0.68 \\
\hline volumic mass $\rho\left(\mathrm{kg} \cdot \mathrm{m}^{-3}\right)$ & 983 & 972 & 963 & 956 \\
\hline static viscosity $\eta\left(\mathrm{kg} \cdot \mathrm{m}^{-1} \cdot \mathrm{s}^{-1}\right)$ & 1.70 & 0.90 & 0.47 & 0.30 \\
\hline kinematic viscosity $\vee\left(\mathrm{x} 10^{-3} \mathrm{~m}^{2} \cdot \mathrm{s}^{-1}\right)$ & 1.73 & 0.925 & 0.49 & 0.315 \\
\hline
\end{tabular}

Table 1: Characteristics of the different polysiloxane-based solutions 


\begin{tabular}{|c|c|c|c|c|c|c|c|}
\hline Rotation speed (rd/min) & 1000 & 1750 & 2000 & 2500 & 3000 & 4000 & 5000 \\
\hline $\begin{array}{l}\text { deposited thickness for } \\
\text { the S1 solution }(\mu \mathrm{m})\end{array}$ & 49.0 & 34.0 & & 24.0 & 20.0 & 14.5 & 12.0 \\
\hline $\begin{array}{l}\text { deposited thickness for } \\
\text { the S2 solution }(\mu \mathrm{m})\end{array}$ & 44.0 & & & 21.5 & 18.0 & 13.5 & 10.5 \\
\hline $\begin{array}{l}\text { deposited thickness for } \\
\text { the S3 solution }(\mu \mathrm{m})\end{array}$ & 41.0 & & 21.5 & 19.0 & 15.0 & 12.0 & 9.5 \\
\hline $\begin{array}{l}\text { deposited thickness for } \\
\text { the } \mathrm{S} 4 \text { solution }(\mu \mathrm{m})\end{array}$ & 36.5 & 22.0 & & 15.0 & 13.5 & 10.0 & 8.5 \\
\hline
\end{tabular}

Table 2: Deposited thickness $\mathrm{h}_{\mathrm{f}}$ for the different polysiloxane-based solutions 


\begin{tabular}{|c|c|c|c|c|c|c|c|c|c|}
\hline Rotation speed (rd/min) & 750 & 850 & 1000 & 1450 & 1500 & 2000 & 2500 & 3200 & 5000 \\
\hline $\begin{array}{c}\text { BCB 4026 deposited } \\
\text { thickness }(\mu \mathrm{m})\end{array}$ & 35.0 & & 22.5 & & 16.7 & 11.8 & 7.9 & & 3.9 \\
\hline $\begin{array}{c}\text { SU8 3050 deposited } \\
\text { thickness }(\mu \mathrm{m})\end{array}$ & & 500 & & 100 & & & & 50.0 & \\
\hline
\end{tabular}

Table 3: Deposited thickness $h_{f}$ for the BCB 4026 and SU8 3050 photosensitive polymers 


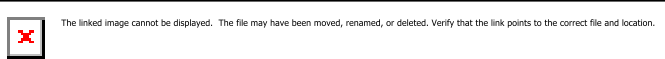

Figure 1: Variations of the final thickness logarithm with the rotation speed logarithm for the different polysiloxane-based solutions 


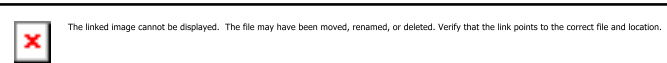

Figure 2: Variations of the final thickness logarithm with the rotation speed logarithm for the BCB 4026 and SU8 3050 photosensitive polymers 